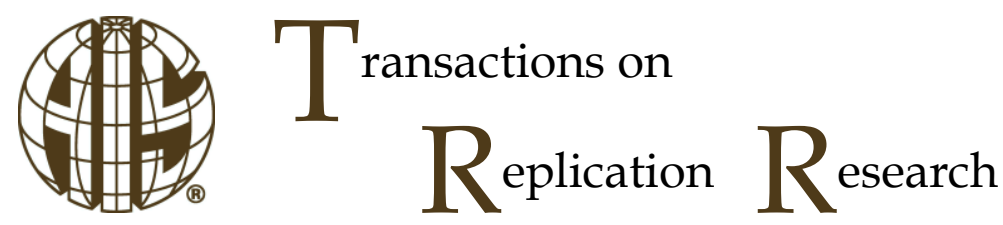

\title{
Examining Longhand vs. Laptop Debate: A Replication Study
}

\author{
Alanah Mitchell \\ Information Management \& Business Analytics \\ College of Business \& Public Administration \\ Drake University, lowa, USA \\ alanah.mitchell@drake.edu
}

\author{
Liping Zheng \\ Economics \& Finance \\ College of Business \& Public Administration \\ Drake University, lowa, USA \\ liping.zheng@drake.edu
}

\begin{abstract}
:
There is a considerable controversy regarding laptop usage in the classroom, with some studies arguing the benefits of laptops in the classroom and others suggesting that a laptop free environment is superior. In an effort to address this controversy, Mueller and Oppenheimer (2014) conducted three different experiments to determine whether typing notes on a laptop or handwriting notes in a notebook impacted academic performance. This research replicated the first of these experiments in a classroom environment as opposed to a lab environment. The original study found that students who did not use laptops for note-taking in class performed better on conceptual application questions, while our study found that students who do not use laptops for note-taking in class performed better on factual recall questions instead. Our updated findings suggest there is more work to do to understand the longhand versus laptop debate.
\end{abstract}

Keywords: Laptops, Note-taking, Technology in classroom, Higher education, Replication

The manuscript was received 04/09/2019 and was with the authors 9 months for 2 revisions. 


\section{Introduction}

There is considerable controversy regarding technology in the classroom. Some studies argue that technology can benefit the classroom in regards to structured activities (e.g., Kay \& Lauricella, 2011). Other studies suggest that a technology free environment is better for learning, with recognition that students are generally distracted by the use of technology in the classroom (e.g., Ragan, Jennings, Massey, \& Doolittle, 2014). In fact, the term "cyber-slacking" has been coined to refer to the use of technology in the classroom for non-class related activities (Rana, Dwivedi, Slade, \& Lal, 2016). It is important for faculty to understand the impact of technology in the classroom. Not only do faculty have to understand the role that laptops, tablets, and phones can play in the classroom; there are now Hands Free Always On (HFAO) technologies, like internet connected watches or rings, that can impact classroom learning outcomes as well (Suasnabar, Lui, Cai, Collins, Bieber, \& Hiltz, 2015).

This research explores technology in the classroom by explicitly focusing on laptop usage in the classroom. In relation to classroom note-taking, there have been controversial findings. For example, there is research that indicates students bring laptops to class for the use of note-taking (Houle, Reed, Vaughan, \& Clayton, 2013). On the other hand, there is research that suggests laptops are a distraction when it comes to keeping notes (Benbunan-Fich \& Truman, 2009; Galluch, Long, Bratton, Gee, \& Groeber, 2009). Likewise, a recent study from Mueller and Oppenheimer (2014) concluded that longhand note-taking is preferable, as students perform better on conceptual questions. The researchers also found that student learning was impaired due to a tendency to transcribe lectures when laptops were used for note-taking. This ultimately leads to shallower information processing, which is not as beneficial for learning as the reframing and understanding of information (Mueller \& Oppenheimer 2014).

Recently, the longhand versus laptop debate has received a lot of attention in the popular press (e.g., Guo, 2016; May, 2017; Rockmore, 2014; Rosenblum, 2017). Primarily, these articles have suggested that students benefit from removing laptops from the classroom. Our research looks at whether or not this perception is true. In general, this topic is of interest to all students and faculty. However, faculty in the field of information systems (IS) should especially be interested due to the fact that IS as a discipline is focused on both the implementation and impact of technology (Benbasat \& Zmud, 2003). The goal of this research is to gain a better understanding of laptop usage in the classroom and its role in note-taking. Specifically, the goal of this research is to replicate the previous study from Mueller and Oppenheimer (2014) to uncover whether or not the findings would be the same, thus helping to settle the controversy of laptop usage in the classroom.

In the original research, Mueller and Oppenheimer (2014) conducted three different experiments to determine whether taking notes on a laptop or handwritten in a notebook impacted academic performance. This research replicates the first of these experiments in a classroom environment as opposed to a lab environment in order to see if the findings are the same in a more practical and realistic setting. If this replication research confirms the findings of the original research, the current study would provide valuable "external third-party validation" (Dennis \& Valacich, 2015). If this replication research does not confirm the findings of the original study, this study would suggest that future research is necessary to solve the laptop in the classroom controversy.

This paper is organized as follows: The next section presents the method for this research, which replicates what was done in the original study (Mueller \& Oppenheimer, 2014). The following section presents results of the replication study and contrasts them with the original study. This research concludes with a discussion, as well as future opportunities for researchers and faculty interested in understanding the use of laptops for note-taking.

\section{Research Methodology}

Mueller and Oppenheimer (2014) conducted three different experiments to determine whether taking notes on a laptop or using longhand handwriting in a notebook impacted academic performance. The method of our research replicated the first of these three experiments in a different context.

The participants from this study included 295 undergraduate (144 male and 149 female) students at a university in the Midwest. Table 1 summarizes the demographic specifics in relation to the previous study. While the gender and condition were evenly split across the two studies, the grade levels did vary in representation. The participant grade level for the current studied varied with $17 \%$ freshman, $28 \%$ sophomores, $23 \%$ juniors, and $33 \%$ seniors. The original study included 67 participants total with $12 \%$ 
freshman, $42 \%$ sophomores, $27 \%$ juniors, and $16 \%$ seniors. An independent-samples t-test was conducted to compare the grade levels from the original study with the current study. There was no significant difference in the grade levels for the two studies $(t(358)=-1.53, p=.13)$.

\begin{tabular}{|c|c|c|}
\hline & Current Study & Original Study \\
\hline $\mathbf{N}$ & 295 & 67 \\
\hline \multicolumn{3}{|l|}{ Gender } \\
\hline Males & 146 & 33 \\
\hline Females & 149 & 33 \\
\hline Unknown & 0 & 1 \\
\hline \multicolumn{3}{|l|}{ Grade Level } \\
\hline Freshman & 49 & 8 \\
\hline Sophmores & 82 & 28 \\
\hline Juniors & 68 & 18 \\
\hline Seniors & 96 & 11 \\
\hline \multicolumn{3}{|l|}{ Condition } \\
\hline Laptop & 145 & 31 \\
\hline Longhand & 150 & 34 \\
\hline
\end{tabular}

For this study, students in a classroom setting were required to watch a TED Talk on how algorithms shape the world ${ }^{1}$ while taking notes. The topic of the video lecture was stimulating, but not common knowledge. As in the original study, students were instructed to use their normal classroom note-taking strategy. However, the participants were split into twelve groups/classes instead of working in a lab two at a time as was done in the original study. Six groups/classes were asked to take notes using their laptops and six groups/classes were asked to take notes via paper. Specifically, one section of each class (e.g., IS class A) was asked to take notes with their laptops and the other section of the same course with the same professor (e.g., IS class B) was asked to take notes via paper. All of the students in a particular section were asked to take notes via the same medium regardless of their preferred note-taking method. Table 2 summarizes the participant specifics by group/class. It should be noted that student participation was voluntary, however students were motivated by extra course credit based on their comprehension of the TED Talk determined by performance on a quiz following the video.

\begin{tabular}{|c|c|c|c|c|c|}
\hline \multicolumn{6}{|c|}{ Table 2. Current Study Group Demographics } \\
\hline Class & Course Title & Condition & Size & Gender & Grade Level \\
\hline 1 & IS - Web Development ${ }^{m}$ & Laptop & 30 & $M: 15 \quad F: 15$ & F: 0 S: $0 \quad \mathrm{~J}: 7$ S: 23 \\
\hline 2 & IS - Web Development ${ }^{m}$ & Longhand & 28 & $\mathrm{M}: 20 \mathrm{~F}: 8$ & F: 1 S: $3 \quad$ J: 7 S: 17 \\
\hline 3 & Econ - Money and Banking ${ }^{z}$ & Laptop & 18 & $\mathrm{M}: 12 \quad \mathrm{~F}: 6$ & F: $0 \quad$ S: $2 \quad \mathrm{~J}: 6$ S: 10 \\
\hline 4 & Econ - International Economics ${ }^{z}$ & Longhand & 25 & $M: 13 \quad F: 12$ & F:2 S: $3 \quad$ J: 9 S: 11 \\
\hline 5 & Econ - Principles of Economics ${ }^{z}$ & Laptop & 28 & $M: 16 \quad F: 12$ & F: $11 \mathrm{~S}: 13 \mathrm{~J}: 4$ S: 0 \\
\hline 6 & Econ - Principles of Economics ${ }^{2}$ & Longhand & 30 & $M: 16 \quad F: 14$ & F: 8 S: 14 J: 4 S: 4 \\
\hline 7 & Econ - Money and Banking ${ }^{z}$ & Laptop & 6 & $\mathrm{M}: 6 \quad \mathrm{~F}: 0$ & F: 0 S: $1 \quad$ J: 4 S: 1 \\
\hline 8 & Econ - Money and Banking ${ }^{z}$ & Longhand & 5 & M: 4 & F: $1 \quad$ S: $0 \quad$ J: 0 S: 4 \\
\hline 9 & Econ - Principles of Economics ${ }^{v}$ & Laptop & 28 & $\mathrm{~F}: 20$ & F: 8 S: 14 J: 5 S: 1 \\
\hline 10 & Econ - Principles of Economics ${ }^{v}$ & Longhand & 36 & $M: 16 \quad F: 20$ & F: 12 S: 15 J: 7 S: 2 \\
\hline 11 & Econ - Principles of Economics ${ }^{h}$ & Laptop & 35 & $M: 11 \quad F: 24$ & F: 3 S: 10 J: 8 S: 14 \\
\hline 12 & Econ - Principles of Economics ${ }^{h}$ & Longhand & 26 & $M: 9 \quad F: 17$ & F: 3 S: $7 \quad$ J: 7 S: 9 \\
\hline
\end{tabular}

\footnotetext{
${ }^{1}$ https://www.ted.com/talks/kevin slavin how algorithms shape our world
} 
After watching the video, students participated in regular classroom activities (i.e., lecture, notes, and in class activities) related to the regular content of the course (i.e., IS or Economics). The topic of the video was not discussed concluding the viewing. Approximately 30 minutes after the watching the video, students took a closed-note quiz based on the video with both factual recall and conceptual application questions (see Appendix A). Consistent with the original study, students did not have an opportunity to review their longhand or laptop notes prior to taking the quiz. Both the selected TED Talk and the quiz questions were used in the original study. The difference from the original study and the replication study is that the students were in a classroom setting as opposed to completing this exercise two at a time in a lab setting. The goal with this change in context was to be more reflective of note-taking in a classroom setting. Additionally, participants in this study were motivated to perform well on the quiz in order to earn extra credit points towards a quiz grade. Students could earn a maximum of 15 extra credit points on this quiz which could be applied towards a regular course quiz grade.

All quizzes were scored by the authors using the same grading scale as the original study. Additionally, the actual notes (both typed and handwritten) were collected and reviewed for word counts and content analysis. In order to compare the notes for content analysis, the handwritten notes from this study were transformed into typed notes by a research assistant. This process was similar to the original study. Any figures or illustrations from the longhand notes were noted in the typed documents but not drawn/included. The following section presents the results from this study in comparison with the original study.

\section{Replication Results}

This section presents the quantitative and qualitative results from our study and contrasts the findings with the original study.

\subsection{Quantitative Results}

The quantitative data analysis for this study followed the same procedure as the original study by analyzing the impact of note-taking medium on quiz performance (Mueller \& Oppenheimer, 2014). However, the original study varied both note-taking medium (laptop vs. longhand) and the video and quiz type (i.e., the original study included four different video/quiz options that could be varied in the lab setting). In the current study, the same video and quiz was used for all participants due to the traditional classroom testing environment (i.e., not lab testing rooms). Due to the use of the same video, there would be no variance in quiz difficulty. Therefore, in the current study, data analysis reviewed the impact of note-taking medium on factual recall questions and conceptual application questions using independent-samples t-tests. Additionally, an analysis of the student's actual note content was conducted, as was done in the original study.

To begin, an independent-samples t-test was conducted to compare the factual recall question scores for students who took notes with laptops compared to students who took notes with notebooks. Our data showed there was a significant difference in scores for laptop students $(M=4.41, S D=1.46)$ and longhand students $(\mathrm{M}=5.05, \mathrm{SD}=1.99), \mathrm{t}(273)=-3.19, \mathrm{p}=.002$ suggesting laptop participants performed significantly worse on factual recall questions. The magnitude of the differences in the means was small (eta squared=.03). This finding was not consistent with the original study, which found that participants performed equally well for factual recall questions.

A second independent-samples t-test was conducted to compare the conceptual application question scores for students who took notes with laptops compared to students who took notes with notebooks. This time, on average longhand students performed slightly better than laptop students, but there was no significant difference in scores for laptop students $(M=1.99, S D=1.44)$ and longhand students $(M=2.14$, $\mathrm{SD}=1.42), \mathrm{t}(291)=-.92, \mathrm{p}=.36$. The magnitude of the differences in the means was very small (eta squared=.003). Statistically speaking, this finding was also not consistent with the original study, which found that laptop participants performed significantly worse on conceptual application questions and not factual recall questions.

In the original study, the number of words was important to analyze as well as student notes verbatim overlap with the TED Talk transcript. Specifically, the original study claimed "participants using laptops are more likely to take lengthier transcription-like notes with greater verbatim overlap with the lecture" (Mueller \& Oppenheimer, 2014, p. 4). Therefore, along with the review of factual recall questions and conceptual application question scores, we also conducted a content analysis of the student notes. Similar to the earlier study, the current study looked at both word count and verbatim overlap of student notes. In the replication 
study, we found that participants who took longhand notes wrote significantly fewer words than those who typed their notes (longhand: $\mathrm{M}=112.49, \mathrm{SD}=57.52$; laptop: $156.59, \mathrm{SD}=80.44), \mathrm{t}(256)=5.38, \mathrm{p}<.001$. Figure 1 shows the difference in means from the current study in comparison with the original study. This finding was consistent with the original study. Both the original study and current study found that students who took notes on a laptop took more notes than students who were using longhand. However, in the current study, students took less notes overall than in the original study. We suspect that this finding is due to students working in a classroom environment instead of in a lab setting. In the original study, participants were recruited through a subject pool and studied two at a time in a lab setting. Perhaps the participants in the original study took more notes overall in an effort to be a valuable research subject. In this study, even though students read through and signed an IRB informed consent form and knew they were a part of a research study, they were still in their regular classroom environment. It is likely that the students in this research study participated in the experience as though they were regularly taking notes for class. This could explain the lower overall word count than in the original study. We suspect that this more realistic environment also resulted in a more realistic capturing of the student note-taking process and results.

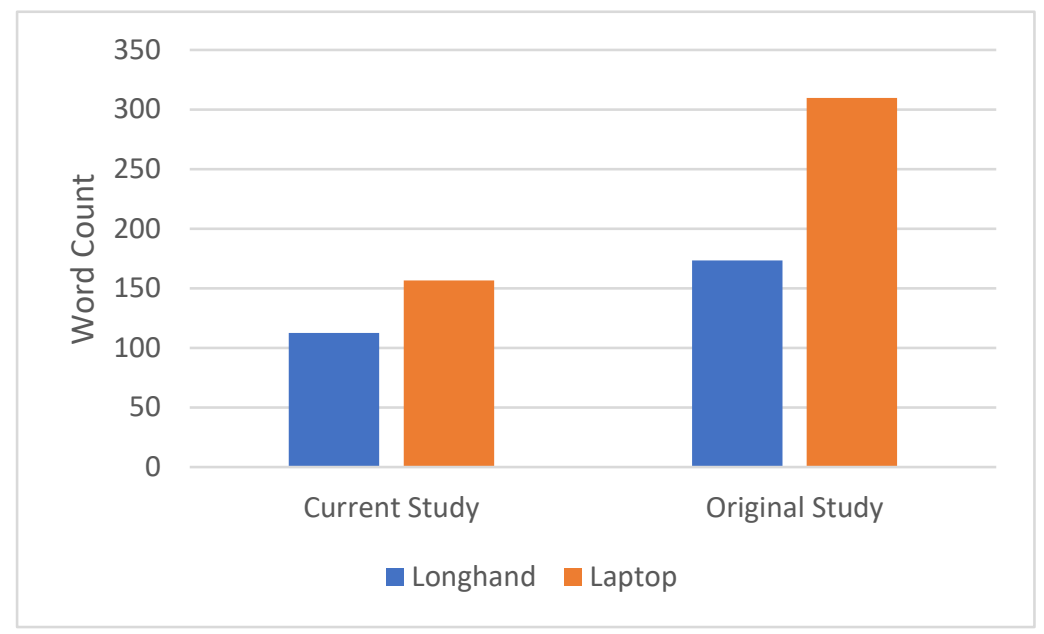

Figure 1. Average Word Count of Student Notes

Further content analysis looked at the verbatim overlap of notes taken in comparison with the actual TED Talk lecture transcript. Specifically, we used a simple $n$-gram program ${ }^{2}$ in order to measure textual overlap between the student notes and the actual lecture transcript. For this step, we compared each three-word chunk (i.e., three-grams) of text in the notes with each three-word chunk of text in the TED Talk lecture transcript to find a percentage match for each participant. This step was similar to the original study. However, our findings in this study were not consistent with the original research. We found laptop notes had an average of $8.3 \%(\mathrm{SD}=.8 \%)$ verbatim overlap with the lecture and longhand notes had an average of $8.1 \%(S D=1.8 \%)$ overlap with the lecture, $t(291)=1.07, p=.28$. Therefore, the difference between the two groups was not significant. Figure 2 shows the comparison of the means from the current and original studies. Similar to the word count comparison, the participants in this study had a lower percentage of overlap across both groups than in the original study. While some of this finding is likely associated with the word count differences (i.e., more words would mean more overlap), it may also be due to the change in context. Either way, the difference in overlap was not found to be significant, which is a not consistent with the original study.

\footnotetext{
${ }^{2}$ http://lextutor.ca/n gram/
} 


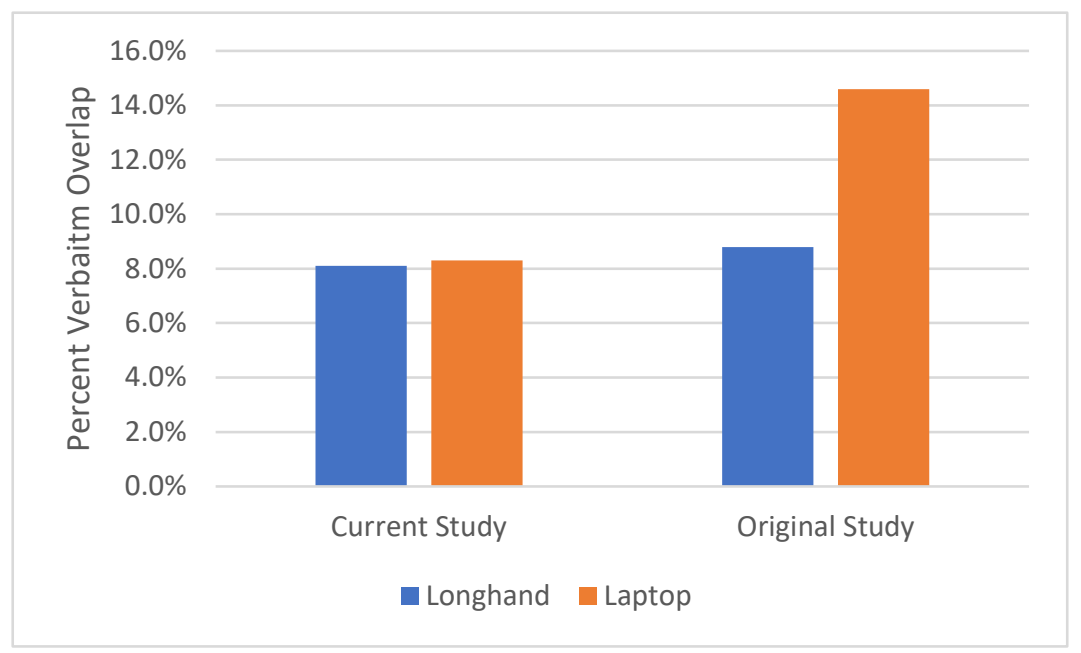

Figure 2. Percentage of Verbatim Overlap Between Student Notes and Lecture Transcript

Finally, this study found that participants who took more notes performed better for factual recall questions with $\beta=0.0017, p=.063, R 2=.09$, but it was not statistically significant for conceptual application questions with $\beta=0.0013, p=.179, R 2=.09$. This result is not consistent with the original study which found it was the case for both types of questions. Verbatim text overlap, was also a positive predictor for the performance on both types of questions but is only significant for factual recall questions with $\beta=10.98, p=.0017, \mathrm{R} 2=$ .0039 for the factual recall questions and $\beta=4.20, p=.379, \mathrm{R} 2=.0039$ for the conceptual application questions. A full comparison of findings across the original and current study are included in Table 3.

\begin{tabular}{|c|c|c|c|}
\hline \multicolumn{4}{|c|}{ Table 3. Results Comparison Across Studies } \\
\hline & Current Study & Original Study & Comparison \\
\hline $\begin{array}{l}\text { Factual recall } \\
\text { performance }\end{array}$ & $\begin{array}{l}\text { Laptop participants performed } \\
\text { significantly worse ( } \mathrm{p} \text {-value }= \\
.002)\end{array}$ & $\begin{array}{l}\text { No significant difference }(p- \\
\text { value }=.91)\end{array}$ & Not consistent \\
\hline $\begin{array}{l}\text { Conceptual } \\
\text { application } \\
\text { performance }\end{array}$ & $\begin{array}{l}\text { No significant difference }(\mathrm{p}- \\
\text { value }=.36)\end{array}$ & $\begin{array}{l}\text { Laptop participants } \\
\text { performed significantly } \\
\text { worse }(p \text {-value }=.03)\end{array}$ & Not consistent \\
\hline Word count & $\begin{array}{l}\text { Longhand notes wrote } \\
\text { significantly fewer words ( } p \text { - } \\
\text { value }<.001 \text { ) }\end{array}$ & $\begin{array}{l}\text { Longhand notes wrote } \\
\text { significantly fewer words ( } p \text { - } \\
\text { value }<.001 \text { ) }\end{array}$ & Consistent \\
\hline $\begin{array}{l}\text { Verbatim } \\
\text { overlap }\end{array}$ & Not significant $(p$-value $=.28)$ & $\begin{array}{l}\text { Laptop participants have } \\
\text { significantly more overlap } \\
\text { (p-value }<.001)\end{array}$ & Not consistent \\
\hline $\begin{array}{l}\text { Note quantity } \\
\text { performance }\end{array}$ & $\begin{array}{l}\text { More notes performed } \\
\text { significantly better for factual } \\
\text { recall questions }(\mathrm{p}=.063) \text { but } \\
\text { no significant difference for } \\
\text { conceptual application } \\
\text { questions }(\mathrm{p}=.179) \\
\end{array}$ & $\begin{array}{l}\text { Overall, more notes } \\
\text { performed significantly } \\
\text { better }(p \text {-value }=.023)\end{array}$ & $\begin{array}{l}\text { Partially } \\
\text { consistent }\end{array}$ \\
\hline $\begin{array}{l}\text { Verbatim } \\
\text { overlap } \\
\text { performance }\end{array}$ & $\begin{array}{l}\text { Less verbatim overlap } \\
\text { performed better but only } \\
\text { signifcant for factual recall ( } p \text { - } \\
\text { value }=.017 \text { and no } \\
\text { significant difference for } \\
\text { conceptual application } \\
\text { questions }(p=.379)\end{array}$ & $\begin{array}{l}\text { Overall, less verbatim } \\
\text { overlap performed } \\
\text { significantly better ( } p \text {-value } \\
=.005 \text { ) }\end{array}$ & $\begin{array}{l}\text { Partially } \\
\text { consistent }\end{array}$ \\
\hline
\end{tabular}


Following Mueller and Oppenheimer (2014), we tested a model using word count and verbatim overlap (three-grams) as mediators of the relationship between note-taking medium and performance using Preacher and Hayes' (2004) bootstrapping procedure with 1000 replications. Mediator variables are variables that sit between independent variable and dependent variable and mediate the effect of the independent variable on the dependent variable. In our model, the independent variable is the note-taking medium and dependent variable is student's performance. A model with two mediators (word count and verbatim overlap) is shown in Figure 3.

Without Mediators

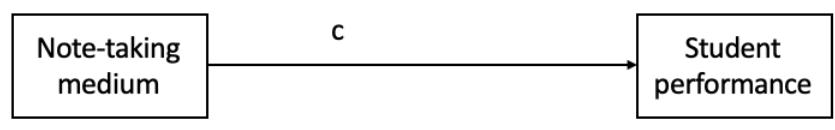

With Mediators

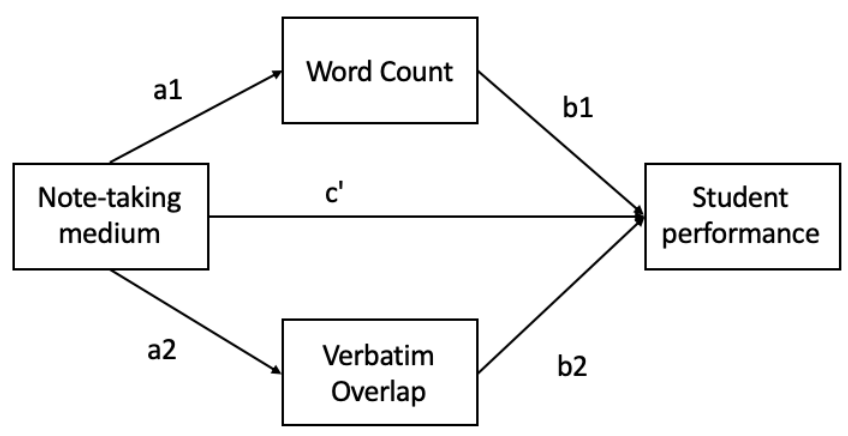

Figure 3. A Model with Two Mediators

In Figure 3, a represents the regression coefficient for the independent variable, note-taking medium, when the mediator variable is regressed on the independent variable. The figure uses $b$ to represent the coefficient for the mediator variable when the dependent variable, student performance, is regressed on the mediator variable and independent variable. Finally, the symbol c' represents the direct effect of the note-taking medium on student performance. In this work, we wanted to determine the indirect effect of note-taking medium on student performance through the two mediating variables, word count and verbatim overlap (a1b1 and a2b2).

Our findings suggest the indirect effect (a1b1 and a2b2) is significant if its $95 \%$ confidence intervals do not include zero. In the full model, the direct effect (c') of note-taking medium is a significant predictor for factual recall question performance, $\beta=0.46, p=.00$ but not for the performance on conceptual application questions; the indirect effect of longhand notetaking on performance through verbatim overlap (a2b2) was not significant while the indirect effect of longhand notetaking through word count (a1b1) was significant only for factual recall questions. Longhand note-taking negatively predicted word count, and word count positively predicted performance on both conceptual application and factual recall questions, with indirect effect $=-0.075,95 \%$ confidence interval $(\mathrm{Cl})=[-0.1718,-0.0022]$ for factual recall questions performance and indirect effect $=-.0568,95 \%$ confidence interval $(\mathrm{Cl})=[-0.1463,0.0187]$ for conceptual application questions performance. The original study found that both indirect effects were significant while we found that only the indirect effect through word count (a1b1) was significant for factual recall questions ${ }^{3}$. As mediation is a hypothesis about a causal network, we must be cautious in interpreting these results. The

${ }^{3}$ Our model results were similar when we use two-grams (instead of three-grams) as a measure of verbatim text overlap and included control variables. 
current study shows that the direct effect (c') was opposite in sign to the indirect effect $(a 1 b 1+a 2 b 2)$, which suggests that the mediators act like suppressor variables. This inconsistent mediation shows that while the relationship between longhand notetaking and performance is supposed to be mediated by word count and verbatim overlap, the total effect of longhand notetaking on performance is smaller than the direct effect. Presumably, the direct effect is positive: Longhand note-taking will help retain information and then lead to better performance. However, as longhand note-taking negatively affects word count and verbatim overlap, likely the effect of word count and verbatim overlap on performance is positive, making the indirect effect negative. A full comparison of the model findings across the original and current study are included in Table 4.

\begin{tabular}{|c|c|c|c|}
\hline \multicolumn{4}{|c|}{ Table 4. Model Comparison Across Studies } \\
\hline & Current Study & Original Study & Comparison \\
\hline $\begin{array}{l}\text { Full model, direct } \\
\text { effect of note- } \\
\text { taking medium on } \\
\text { performance }\end{array}$ & $\begin{array}{l}\text { Significant predictor for factual } \\
\text { recall question performance, } \beta \\
=0.46, p=.00 \text { but } n o t \\
\text { significant for conceptual } \\
\text { application performance }\end{array}$ & $\begin{array}{l}\text { A marginally significant } \\
\text { predictor, } \beta=0.27, p= \\
.07\end{array}$ & $\begin{array}{l}\text { Not } \\
\text { consistent }\end{array}$ \\
\hline $\begin{array}{l}\text { Full model with } \\
\text { note-taking } \\
\text { medium as } \\
\text { independent } \\
\text { variable and word } \\
\text { count and } \\
\text { verbatim overlap } \\
\text { as mediators } \\
\end{array}$ & $\begin{array}{l}\text { Significant predictor for factual } \\
\text { recall question performance, } \\
F(3,263)=9.54, p=0.00, R^{2}= \\
.089, \text { but } n o t \text { a significant } \\
\text { predictor for conceptual } \\
\text { application performance, } F(3, \\
263)=1.94, p=0.12, R^{2}= \\
.0195\end{array}$ & $\begin{array}{l}\text { A significant predictor of } \\
\text { performance, } F(3,61)= \\
4.25, p=.009, R^{2}=.17\end{array}$ & $\begin{array}{l}\text { Not } \\
\text { consistent }\end{array}$ \\
\hline $\begin{array}{l}\text { Impact of note- } \\
\text { taking medium on } \\
\text { word count and } \\
\text { performance }\end{array}$ & $\begin{array}{l}\text { Longhand note-taking } \\
\text { negatively predicted word } \\
\text { count; word count positively } \\
\text { predicted performance for both } \\
\text { types of questions } \\
\text { Factual recall, indirect effect = } \\
-0.075,95 \% \text { confidence } \\
\text { interval }(\mathrm{Cl})=[-0.1718, \\
-0.0022] \\
\text { Conceptual application, indirect } \\
\text { effect }=-.0568,95 \% \\
\text { confidence interval }(\mathrm{Cl})= \\
{[-0.1463,0.0187]}\end{array}$ & $\begin{array}{l}\text { Longhand note-taking } \\
\text { negatively predicted word } \\
\text { count; word count } \\
\text { positively predicted } \\
\text { performance } \\
\text { Overall, indirect effect = } \\
-0.57,95 \% \text { confidence } \\
\text { interval }(\mathrm{Cl})=[-1.03 \text {, } \\
-0.20]\end{array}$ & Consistent \\
\hline $\begin{array}{l}\text { Impact of note- } \\
\text { taking medium on } \\
\text { verbatim overlap } \\
\text { and performance }\end{array}$ & $\begin{array}{l}\text { Longhand note-taking } \\
\text { negatively predicted verbatim } \\
\text { overlap; but verbatim overlap } \\
\text { positively predicted } \\
\text { performance for both types of } \\
\text { questions } \\
\text { Factual recall, indirect effect = } \\
-0.0193,95 \% \text { confidence } \\
\text { interval }(\mathrm{Cl})=[-0.066,0.009] \\
\text { Conceptual application, indirect } \\
\text { effect }=-.0073,95 \% \\
\text { confidence interval }(\mathrm{Cl})= \\
{[-0.0352,0.0042]}\end{array}$ & $\begin{array}{l}\text { Longhand note-taking } \\
\text { negatively predicted } \\
\text { verbatim overlap; } \\
\text { verbatim overlap } \\
\text { negatively predicted } \\
\text { performance } \\
\\
\text { Overall, indirect effect = } \\
0.34,95 \% \mathrm{Cl}=[0.14 \text {, } \\
0.71]\end{array}$ & $\begin{array}{l}\text { Not } \\
\text { consistent }\end{array}$ \\
\hline
\end{tabular}


Essentially, our findings suggest laptops may help academic performance as they can be used to help students take more notes which leads to better performance on factual recall questions. This indirect effect through word count is consistent with the findings by Mueller and Oppenheimer (2014) but the indirect effect through verbatim is not consistent with the original findings as the verbatim overlap with the lecture has negative but insignificant impact on performance.

\subsection{Quantitative Results}

Along with the quantitative results from this study, qualitative feedback was gathered from the participants. This section explores some of these findings.

When asked about note-taking preferences, 84 of the participants selected laptop as their preference for notetaking. Most of the students who chose laptop as their preference attributed their selection to speed. Comfort was also mentioned by some students. For example, one student wrote: "I can take down notes faster, writing causes finger pain." Others mentioned access, convenience, search-ability, and even pagedesign as reasons for preferring laptops. Table 5 shows some of the student comments related to laptop preference.

\begin{tabular}{|l|l|}
\hline \multicolumn{2}{|c|}{ Table 5. Student Comments Regarding Laptop Preference } \\
\hline No. & Student Comment \\
\hline 1 & "able to type faster than write, easier to read and organize" \\
\hline 2 & "easier to organize in folders" \\
\hline 3 & "easier to comb through later, highlight, move around" \\
\hline 4 & $\begin{array}{l}\text { "I am able to catch more of the important info in whole. I type } 4 X \text { faster } \\
\text { than I write. Able to get inf then go back and write it down to study" }\end{array}$ \\
\hline 5 & "most of my lectures are PPTs, so I take notes on each slide" \\
\hline 6 & $\begin{array}{l}\text { "I write slow and don't catch all the important information when I write } \\
\text { my notes" }\end{array}$ \\
\hline 7 & "convenient for note taking, refer back to notes" \\
\hline
\end{tabular}

On the other hand, 192 of the participants selected notebook as their preference for notetaking. (Note: 17 students did not answer this question on the survey or instead wrote in the word "both" or "depends.") Most of the students, who chose notebooks as their preference, attributed their selection to better recall/memory. For example, one student stated: "I can remember what I write, not what I type." Many students also mentioned that notebooks were less "distracting" while in class. For example, one student commented that a "laptop is too distracting, which is why my GPA is bad now." Other students mentioned the ability to "design" their handwritten notes easier or copy math formulas easier. One student even mentioned that handwritten notes were more reliable, stating, "My laptop breaks all the time. I like hard copy." Table 6 shows some of the student comments for longhand/notebook preference.

\begin{tabular}{|l|l|}
\hline \multicolumn{2}{|c|}{ Table 6. Student Comments Regarding Longhand Preference } \\
\hline No. & Student Comment \\
\hline 1 & "easier to remember, no distraction" \\
\hline 2 & $\begin{array}{l}\text { "I don't like hauling around my laptop. Also I prefer having a hard copy } \\
\text { of notes. I also like to doodle and sketch." }\end{array}$ \\
\hline 3 & $\begin{array}{l}\text { "it is easier to format to what you want and helps you remember what } \\
\text { you are learning" }\end{array}$ \\
\hline 4 & $\begin{array}{l}\text { "comprehend better because I am actually writing, taking high quality } \\
\text { notes" }\end{array}$ \\
\hline 5 & "teachers don't allow laptops" \\
\hline 6 & "it helps me retain information better, I hate the light from my screen" \\
\hline 7 & "I can make my own diagrams and symbols much faster." \\
\hline
\end{tabular}


Overall, the participants overwhelming preferred longhand to laptops for their notetaking. A number of comments suggested that students believe handwritten notes help most with memory. For example, one student commented, "I have heard that handwriting notes helps with memory retention." Perhaps this particular student had seen some of the popular press articles suggesting that longhand is preferable (e.g., Guo, 2016; May, 2017; Rockmore, 2014; Rosenblum, 2017). Other comments suggested that the use of laptops in the classroom is faculty driven. For example, one student stated, "If we need laptops for class I use that to take notes. If I don't need a laptop then I use a notebook." Another stated: "professor doesn't allow laptops=>become habit." These attributions to research support and faculty policies present some interesting ideas for future research, which are presented in the following section.

\section{Discussion and Conclusion}

\subsection{Interpretation of Results}

The goal of this study was to follow up earlier work which provided initial experimental evidence that laptops were not beneficial for use in the classroom, specifically in relation to note-taking. This study replicated an experiment designed by Mueller and Oppenheimer (2014) where students were shown a lecture and either took notes via a laptop or using longhand in a notebook. This study was different from the original study in that the experiment took place in a classroom setting as opposed to a two-person lab environment. The original study found that students who did not use laptops for note-taking in class performed better on conceptual application questions, which was not significantly confirmed in our study. However, our findings supported quite the opposite suggesting that students who did not use laptops for note-taking in class performed better on factual recall questions. In relation to content analysis, our findings did support the original study when looking at the content analysis of student notes. Specifically, word count of student notes was significantly higher for students who were taking notes in their laptops than using longhand. On the other hand, there was not a significant difference of student notes with regard to verbatim overlap of lecture content as there was in the original study. Finally, our results did show that students who take more notes performed better, but only for factual questions. Moreover, the original study found that both indirect effects were significant while we found that only the indirect effect though word count was significant for factual recall questions, not for the conceptual application questions.

Overall, our findings suggest laptops may help academic performance as they can help students take more notes which leads to better performance. This indirect effect through word count is consistent with the findings by Mueller and Oppenheimer (2014) but the indirect effect through verbatim is not consistent with the original findings as the verbatim overlap with the lecture has negative but insignificant impact on performance. However, we also found that students who take longhand notes do perform significantly better on factual recall questions. Perhaps it is the case that students who are handwriting a lot of notes will be the most successful.

Generally, replication research offers a contribution if it provides "external third-party validation" to the original study's findings (Dennis \& Valacich, 2015). The fact that our findings do not fully confirm the findings from the original study, suggests that future research is necessary to solve the laptop usage in the classroom controversy. However, the current study included a couple of key differences from the original study which may play a factor in interpreting the differences in our results. Specifically, the current study had two key differences from the original study. First of all, the students in the current study were students in their regular classroom with their regular instructor and classmates as opposed to the original study which recruited volunteers to participate in a two-person lab study. In the current study, students took less notes overall and had a lower percentage of verbatim overlap than in the original study. We suspect this finding is due to students working in a classroom environment instead of in a lab setting. Likely the students in the current study took notes following their normal classroom behavior as they were in a setting with an instructor and classmates they were regularly with, as opposed to put into a lab setting to participate in an experiment. The second difference from the original study and the current study is the same video and quiz were used for all students while the original study included four different video/quiz options. The original study noted there were differences in quiz question difficulty and points available when different videos/quizzes were used. The students in the current study were working together in a regular classroom where it would be more difficult to show different videos. While this difference does not seem to have had an impact, it should be noted.

Another possible explanation of our results could be related to the differences of student bodies. We did conduct a simple t-test to see if there were any differences based the grade level distribution demographic 
(e.g., Freshman, Sophomore, Junior, and Senior) and found none. However, it may be possible that other student demographic differences could impact test performance (e.g., majors, background, note-taking skills, or even note-taking preference).

\subsection{Research Implications}

As mentioned earlier, IS as a discipline is focused on both the implementation and impact of technology (Benbasat \& Zmud, 2003). Therefore, understanding the impact of technology, like laptops, on performance is an interest to the field. In fact, there are a couple of IS theories related to task-technology fit which might help to explain some of the findings from this area of study. Media richness theory (MRT) presents a model for finding the most appropriate medium for processing information and therefore facilitating understanding (Daft \& Lengel, 1986). Task-Technology Fit (TTF) partners task types based on complexity with the best matched technology (Zigurs \& Buckland, 1998). Finally, Fit Appropriation Model (FAM) looks for an appropriate fit between task type and technology capabilities while including appropriation support (e.g., guidance, facilitation, training) (Dennis, Wixom, \& Vandenberg, 2001). Some of the primary differences between laptop and longhand note-taking are related to math equations, drawings, and figures. Arguably, and reflected some of the qualitative comments from this study, it is easier and faster to write equations, draw relationships, and visualize concepts with paper and pen than it is with a laptop. Each of these IS theories suggests there should be an appropriate fit between the task at hand and the technology used to accomplish that task. Our study confirms there is a potentially a disconnect between how laptops are being used (or not used) for note-taking in the classroom (e.g., should students concerned with factual recall, use laptops or longhand?). Although theories of task-technology fit have been studied in relation to various tasks, there seems to be a gap in relation to understanding laptop and note-taking best practices.

A second area of research implications is related to the influential factor of student note-taking preference. In both the original and current study, students were assigned a condition which may or may not have matched their personal note-taking preference. However, at the conclusion of both studies, students were asked about their preference. In the current study, students overwhelming reported preferring longhand over laptops. Also, interestingly, the qualitative findings from our study seemed to suggest the lack of use of laptops in the classroom can be faculty driven. In fact, multiple students mentioned they have some faculty members who do not allow the use of laptops in the classroom. This adaption of the students' notetaking habits to the cues of the professor is a potentially interesting avenue for exploration. Relatedly, Adaptive Structuration Theory (AST) offers an approach for studying the role of technology beginning with social structures or rules as a starting point, similar to the idea of a faculty driven rule or guideline in the classroom environment (DeSanctis \& Poole, 1994). Understanding laptop usage or adaptation based on faculty rules or classroom guidelines may be another area lacking best practice recommendations.

\subsection{Professional Implications}

The publication of the original Mueller and Oppenheimer (2014) prompted much attention from the popular press regarding the longhand versus laptop debate (e.g., Guo 2016; May 2017; Rockmore 2014; Rosenblum 2017). In fact, more recent articles are even making a case for the use of longhand on electronic devices (Pierce, 2018). The goal of this study was not to criticize or question lab studies, but simply to replicate the original study in a realistic classroom setting in order to truly understand the usefulness (or uselessness) of laptops in the classroom. However, what this research has shown is the value of research replication. Based on the popular press articles and the overwhelming preferences and comments from students in this study, popular opinion has formed suggesting that laptops are not ideal for note-taking in the classroom. However, our replication of the original study suggests that laptops may help academic performance as they can be used to help students take more notes which leads to better performance on factual recall questions.

What should faculty do in their own classrooms based on the findings from this study? Faculty may try using published research (e.g., Mueller \& Oppenheimer 2014; Ragan et al. 2014; Rana et al. 2016) to inform students of their classroom policies regarding laptops (and other technologies) in the classroom. Faculty who are interested in the debate over the use of laptops in the classroom might try prohibiting the use of laptops in the classroom. If a laptop is required in the classroom due to the subject at hand but a faculty member is concerned about the distraction of laptops or other technology in the classroom, there could be other solutions. For example, previous research has presented the use of more discussion and active learning exercises in the classroom as a possible solution for limiting laptop usage (Griffin, 2014). Faculty might also try making notes available to students in different formats (e.g., Worthington \& Levasseur, 2015) or provide some training on effective note-taking skills in the classroom (e.g., McGuire, 2015). 


\subsection{Future Research}

Due to the fact the replication findings from this study were not consistent with the original study, a number of avenues for future research remain. To begin, future research should consider the impact of tasktechnology fit theories (e.g., MRT, TTF, and FAM) related to the task of note-taking and the use of laptop technology. An understanding of these theories, in this context, could drive faculty policies in the classroom. In addition, future research should explore the impact of faculty and classroom policies regarding laptop usage on student preferences (e.g., AST). Specifically, what is the impact if the classroom policy differs from student preference?

Future research might also consider the use of laptops and other technologies intermittently during class. For example, it may be the case that a faculty member only involves laptops at certain points during the class and not the entire class period. However, this may still result in challenges. While some technology can be easily removed from the classroom (e.g., laptops, tablets, phones) there are emerging technology innovations like HFAO technologies that are making this more difficult.

Finally, future research may need to consider discipline differences regarding laptops in the classroom. Perhaps it is the case that different disciplines or course subjects have an easier time removing laptops (and other technologies) from the classroom (e.g., math, economics, accounting, chemistry). However, some courses require the use of laptops due to the subject at hand (e.g., IS, computer science, statistics).

\subsection{Conclusion}

In summary, our replication of Mueller and Oppenheimer (2014) only partially supports some of their conclusions. Therefore, what this study concludes is that further research is certainly needed to help solve the debate of laptop use and value in the classroom related to both current and emerging technologies.

\section{Acknowledgments}

The authors would like to thank Heath Henderson and Brian Vander Naald for their help with data collection.

\section{References}

Benbasat, I., \& Zmud, R. W. (2003). The identity crisis within the IS discipline: Defining and communicating the discipline's core properties. MIS Quarterly, 27(2), 183-194.

Benbunan-Fich, R., \& Truman, G. E. (2009). Multitasking with laptops during meetings. Communications of the ACM, 52(2), 139-141.

Daft, R., \& Lengel, R. (1986). Organizational information requirements, media richness, and structural design. Management Science, 32(5), 554-571.

Dennis, A. R., \& Valacich, J. S. (2015). A replication manifesto. AIS Transactions on Replication Research, $1,1-4$.

Dennis, A. R., Wixom, B. H., \& Vandenberg, R. J. (2001). Understanding fit and appropriation effects in group support systems via meta-analysis. MIS Quarterly, 25(2), 167-193.

DeSanctis, G., \& Poole, M. S. (1994). Capturing the complexity in advanced technology use: Adaptive structuration theory. Organization Science, 5(2), 121-147.

Galluch, P., Long, C., Bratton, T., Gee, M., \& Groeber, M. (2009). Losing the battle: Student and instructor perspectives on attention loss in the classroom. Paper presented at Southern Association for Information Systems (SAIS), Charleston, SC.

Griffin, A. (2014). Technology distraction in the learning environment. Paper presented at Southern Association for Information Systems (SAIS), Macon, GA.

Guo, J. (2016, May 16). Why smart kids shouldn't use laptops in class. The Washington Post. Retrieved from https://www.washingtonpost.com/news/wonk/wp/2016/05/16/why-smart-kids-shouldnt-uselaptops-in-class/

Houle, P. A., Reed, D., Vaughan, A. G., \& Clayton, S. R. (2013). Using laptop computers in class: A Student motivation perspective. Journal of Learning in Higher Education, 9(2), 83-92. 
Kay, R. H., \& Lauricella, S. (2011). Unstructured vs. structured use of laptops in higher education. Journal of Information Technology: Innovations in Practice, 10, 33-42.

May, C. (2017, July 11). Students are better off without a laptop in the classroom. Scientific American. Retrieved from https://www.scientificamerican.com/article/students-are-better-off-without-a-laptopin-the-classroom/

McGuire, S. Y. (2015). Teach students how to learn: Strategies you can incorporate into any course to improve student metacognition, study skills, and motivation. Stylus Publishing LLC.

Mueller, P. A., \& Oppenheimer, D. M. (2014). The pen is mightier than the keyboard: Advantages of longhand over laptop note taking. Psychological Science, 25(6), 1159-1168.

Pierce, D. (2018, July 15). Smartphones killed handwriting. Let's bring it back. Wall Street Journal. Retrieved from https://www.wsi.com/articles/smartphones-killed-handwriting-lets-bring-it-back-1531659601

Preacher, K. J., \& Hayes, A. F. (2004). SPSS and SAS procedures for estimating indirect effects in simple mediation models. Behavior Research Methods, Instruments, and Computers, 36, 717-731.

Ragan, E. D., Jennings, S. R., Massey, J. D., \& Doolittle, P. E. (2014). Unregulated use of laptops over time in large lecture classes. Computers \& Education, 78, 78-86.

Rana, N., Dwivedi, Y., Slade, E., \& Lal, B. (2016). Cyber-slacking: Exploring students' usage of internetenabled devices for non-class related activities. Paper presented at Americas Conference on Information Systems (AMCIS), San Diego, CA.

Rockmore, D. (2014, June 6). The case for banning laptops in the classroom. The New Yorker. Retrieved from https://www.newyorker.com/tech/elements/the-case-for-banning-laptops-in-the-classroom

Rosenblum, D. (2017, January 2). Leave your laptops at the door to my classroom. The New York Times. Retrieved from https://www.nytimes.com/2017/01/02/opinion/leave-your-laptops-at-the-door-to-myclassroom.html

Suasnabar, E. S., Lui, Y., Cai, X., Collins, R., Bieber, M., \& Hiltz, S. R. (2015). How hands free always on (HFAO) technology will affect classrooms. Paper presented at Americas Conference on Information Systems (AMCIS), Puerto Rico.

Worthington, D. L., \& Levasseur, D. G. (2015). To provide or not to provide course PowerPoint slides? The impact of instructor-provided slides upon student attendance and performance. Computers \& Education, 85, 14-22.

Zigurs, I., \& Buckland, B. K. (1998). A theory of task/technology fit and group support systems effectiveness. MIS Quarterly, 22(3), 313-334. 


\section{Appendix A: Quiz Questions}

Factual recall and conceptual application questions for TED Talk lecture (Mueller \& Oppenheimer, 2014)

Kevin Slavin - How Algorithms Shape Our World:

https://www.ted.com/talks/kevin slavin how algorithms shape our world

1. (conceptual - 2pts) How are algorithms useful for successful stock trading?

2. (factual - 1pt) What percentage of the trading activity on the U.S. stock market is done by algorithms?

3. (conceptual - 2pts) What are two problems that have resulted from algorithms being in control of important functions?

4. (factual - 1pt) What is the name of the algorithm that determines $60 \%$ of the movies rented through Netflix?

5. (conceptual - 2pts) How does the altered picture of the mountain range at the beginning of the talk connect with the speaker's main point?

6. (factual - 2pts) Between what two cities is the trench for fiber-optic cable to increase signal speed being built?

7. (factual $-1 \mathrm{pt}$ ) Which of these is not the name of an algorithm the speaker mentioned in the talk?

a. The Boston Shuffler

b. The Carnival

c. The Knife

d. The Sniper

8. (factual - 1pt) What do Epogogix's algorithms claim to be able to do?

9. (factual - 1pt) What is the Boston company that finds and catalogs stock-trading algorithms called?

10. (factual - 2pts) In New York City, where is the Internet distributed from?

Demographic questions based on Mueller and Oppenheimer (2014)

1. How much knowledge related to the topic of the talk did you have before today?

a. $1=$ None at all; $5=$ Expert Knowledge

2. Please briefly describe your prior experience with/knowledge of the topic, if any.

3. What year will you graduate?

4. What is your GPA?

5. What is your major (if you have decided on one)?

6. What was your ACT score?

7. Do you normally take notes in class on your laptop or in a notebook? Why?

8. In general, do you think it is better for learning purposes to take notes on a laptop or in a notebook?

a. $1=$ Laptop significantly better; 7 = Notebook significantly better

9. Does your choice to take notes on a laptop or in a notebook differ depending on whether it is a humanities, science, or math course?

10. How long do you normally spend reviewing notes when studying for a test?

11. Do you have any other thoughts regarding note-taking on a laptop vs. in a notebook? 


\section{About the Authors}

Alanah Mitchell is an Associate Professor of Information Systems in the Department of Information Management and Business Analytics in the College of Business and Public Administration at Drake University. Her Ph.D. is in Information Technology from the University of Nebraska at Omaha. Professor Mitchell's research focuses on the design, implementation, and use of information and communication technologies for collaboration, specifically in global virtual teams. Additionally, she researches in areas of e-commerce, analytics, and pedagogy. She has published in such journals as Journal of the Association for Information Systems, Communications of the Association for Information Systems, DATA BASE, International Journal of e-Collaboration, and American Journal of Business as well as others.

Liping Zheng is an Associate Professor of Economics in the Department of Economics and Finance in the College of Business and Public Administration at Drake University. Her Ph.D. is in Economics from the University of New Hampshire. Professor Zheng's research focuses on macroeconomics, specifically in the financial markets. Additionally, she researches in the pedagogy of economics. She has published in such journals as Economic Analysis and Policy, International Journal of Economics and Finance, International Research Journal of Applied Finance, and Journal of Applied Finance and Banking as well as others.

Copyright $@ 2019$ by the Association for Information Systems. Permission to make digital or hard copies of all or part of this work for personal or classroom use is granted without fee provided that copies are not made or distributed for profit or commercial advantage and that copies bear this notice and full citation on the first page. Copyright for components of this work owned by others than the Association for Information Systems must be honored. Abstracting with credit is permitted. To copy otherwise, to republish, to post on servers, or to redistribute to lists requires prior specific permission and/or fee. Request permission to publish from: AIS Administrative Office, P.O. Box 2712 Atlanta, GA, 30301-2712 Attn: Reprints or via e-mail from ais@aisnet.org. 